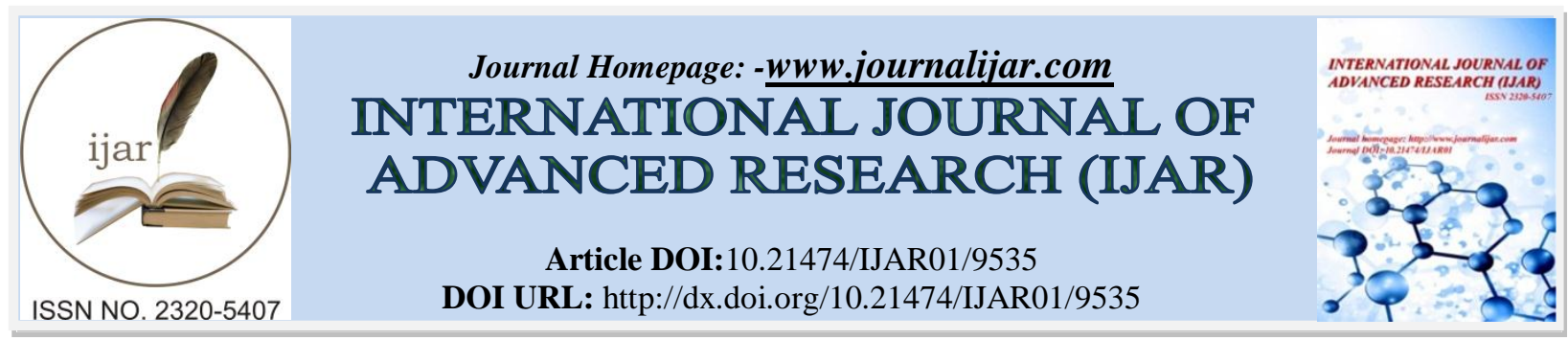

RESEARCH ARTICLE

\title{
EPIDEMIOLOGY OF STRABISMUS AMONG PATIENTS VISITING SQUINT CLINIC IN BENGHAZI.
}

\section{Adam M.Elbarghathi ${ }^{1,3}$,Mohammed F.Elbarghathi ${ }^{2,3}$ and Ruwida M.Abdullah ${ }^{2,3}$.}

1. The dean of faculty of medicine, University of Benghazi, Libya.

2. MSc student, Ophthalmology department, Faculty of medicine, University of Benghazi, Libya.

3. The Martyr Sohil Alatrash Eye Hospital, Benghazi, Libya.

\section{Manuscript Info}

Manuscript History

Received: 08 June 2019

Final Accepted: 10 July 2019

Published: August 2019

\section{Abstract}

Copy Right, IJAR, 2019,. All rights reserved.

\section{Introduction:-}

Strabismus /squint (ocular misalignment) is a widespread problem affecting young children, it's described centuries back when Hippocrates tried to find out its causes and noticed its familial inheritance (1).Still, the causes of concomitant strabismus - in which the amount of deviation in the squinting eye remains constant (unaltered) in all the directions of gaze - is unclear with many hypothesis and genetic studies to localize the exact causative (2) to obtain the best visual and cosmetic outcome.

Early strabismus presentation is fundamental for diagnosis, getting full ocular, refractive and orthoptic examination plus elimination of organic (non refractive) causes to get the best visual binocular rehabilitation before amblyopia is established.

The main challenge in squint management in Libya as other parts of the world is the stigma behind (3) and the psychosocial impacts which leads to gender based discrimination (3), low self esteem (4), with lower health-related quality of life (5); plus denying the causative factors and the noninvasive early refractive and orthoptic management which will not only improve its cosmetic impact but obtains the best visual binocular outcome which is the main goal.

Due to the lack of previous literature in Libya about squint prevalence, common types, influencing factors and it's associated refractive status, we tried to review the demographic, refractive, orthoptic status of recorded patients visiting squint clinic in Marytr Souhil Alatrash eyes teaching hospital in Benghazi in order to get enhanced understanding to the situation and elicit the weakness points to get the best outcome.

\section{Materials And Methods:-}

633 patients were registered in the squint clinic in Marytr Souhil Alatrash eyes teaching hospital hospital between (2006- 2016) as cases of concomitant squint patients were transferred from the outpatient departments after primary slit lamp examination and elimination any organic defect and suspicion of ocular misalignment.

In only 605 of them demographic information, history and examination were reported fully as cases of concomitant strabismus, Patients were excluded if they had previous ocular surgery, ocular trauma or any other organic or coexisting eye diseases.Ophthalmic examinations were performed by a team of two senior ophthalmologists, two juniors, and two optometrists .

Corresponding Author: - Ruwida M.Abdullah.

Address:- MSc student, Ophthalmology department, Faculty of medicine, University of Benghazi, 
In the beginning any dysmorphic features and/or abnormal head posture, pseudo strabismus was noted. Ocular alignment was assessed by means of Hirschberg test, the cover-uncover test and the alternate cover test with fixation targets at both $33 \mathrm{~cm}$ (near) and 6 meters (distant). Binocular and monocular ocular movements were assessed at nine diagnostic positions of gaze. If strabismus was noted, a prism cover test was performed to detect the degree of misalignment.

Patients had the measurement of refractive error using an autorefractor (TOPCON) under cycloplegic conditions plus retinoscopy. One drop of topical $1.0 \%$ cyclopentolate for children over 5 years was administered to each eye twice at 10-minute intervals. Fifteen minutes later, a third drop of cyclopentolate was administered. In children younger than 5 years Atropine $1 \%$ was used three times a day three days prior to examination ; refractive errors were reported if any and their spherical equivalent was calculated (spherical equivalent $(\mathrm{SE})=\mathrm{sphere}+1 / 2$ cylinder). Detailed dilated fundus examination was done too by direct or indirect ophthalmoscopy to eliminate any defects .Spectacles were prescribed once required, occlusion therapy was advised to eliminate amblyopia with different protocols (6) (7), went into regular follow up according to the age and amblyopia risk till getting best visual outcome, other cases were referred for surgical intervention when essential.

Data was entered and analyzed on SPSS version 23.00 Quantitative variables were presented as mean and standard deviation. Qualitative variables were presented in terms of frequency and percentages.

\section{Results:-}

\section{Age at presentation}

Patients ages ranged between 3 months and 24years(Figure 1),76.5\% (463) of them were presented to the squint clinic seeking management before six years of life , 41.5\%(251) of them presented between 3and 6 years of age , the mean age of presentation was $=5.076, \mathrm{SD}(\mathrm{Standard}$ Deviation $) \pm 3.4127$, and the mode age was 4 .

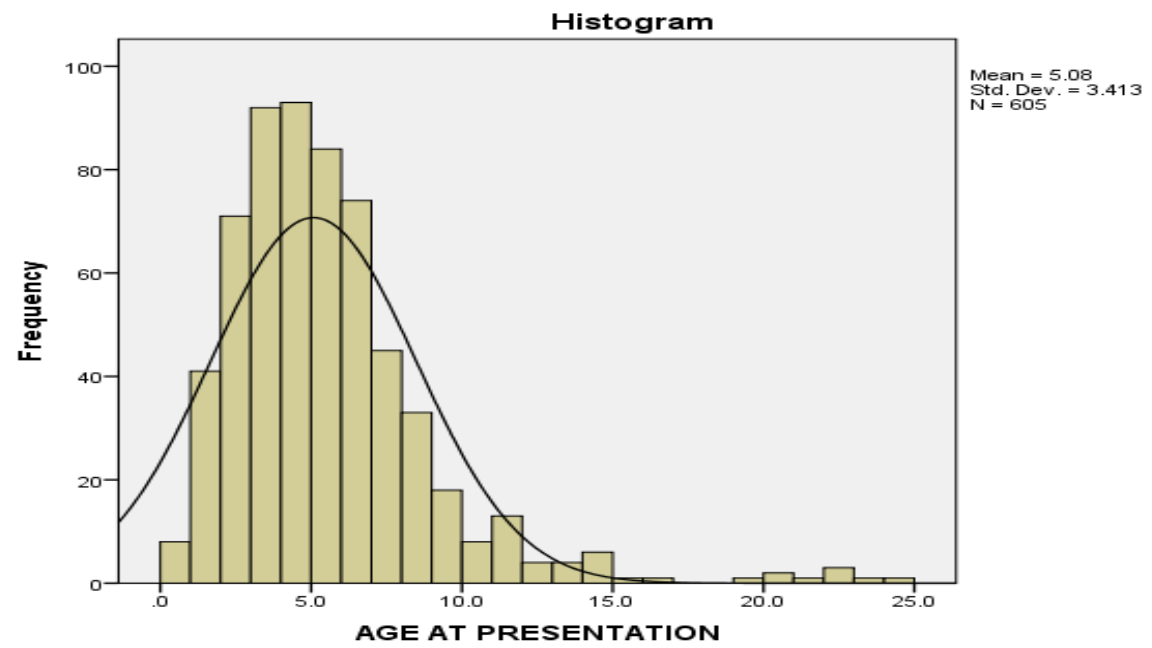

Figure 1:-Histogram representing age frequency of 605 concomitant squint patients, with mean age of 5.08

\section{Gender and Presentation}

$52.4 \%(317)$ of patients registered were females, female :male ratio was 1.1:1, boys were presented earlier with mean age 4.757 SD \pm 2.9834 (Figure 2), while girls presented later with a mean age of =5.366 SD \pm 3.7417 (Figure 3). 


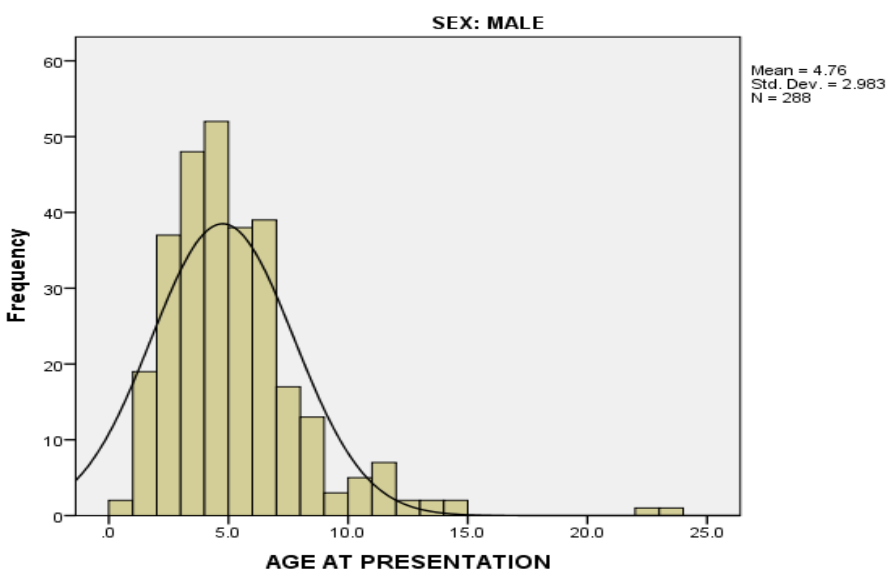

Figure 2:-Histogram representing frequency of 288 male patients ages, with a mean age of 4.76 years.

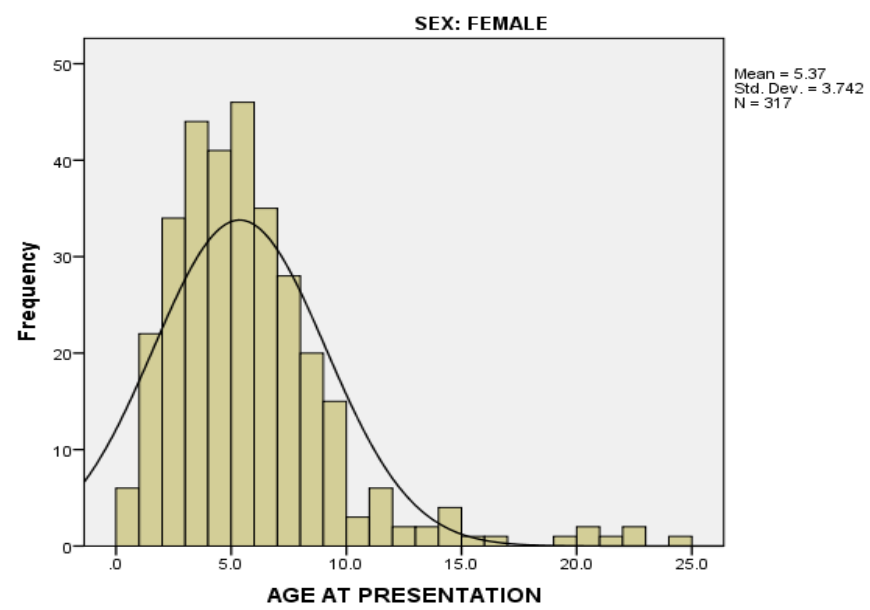

Figure 3:-Histogram representing frequency of 317 female patients ages, with a mean age of 5.37 years.

\section{Squint Presentation}

Esotropia represents $86.4 \%$ of the cases, constant type was the most common with $57.5 \%$ (348), while alternative type represents $28.9 \%$ of the cases both of them had nearly equal presentation in both sex. Apparent squint was seen only in 10 cases $(1.7 \%$ ), exotropia was presented in $10.7 \%$ of the cases $6.9 \%$ of them were of alternative element. This gives esotropia to exotropia ratio of 8.075:1(Figure 4) .

Only in two cases hyperphoria was noted, and the same number for $\mathrm{A} \& \mathrm{~V}$ patterns. 


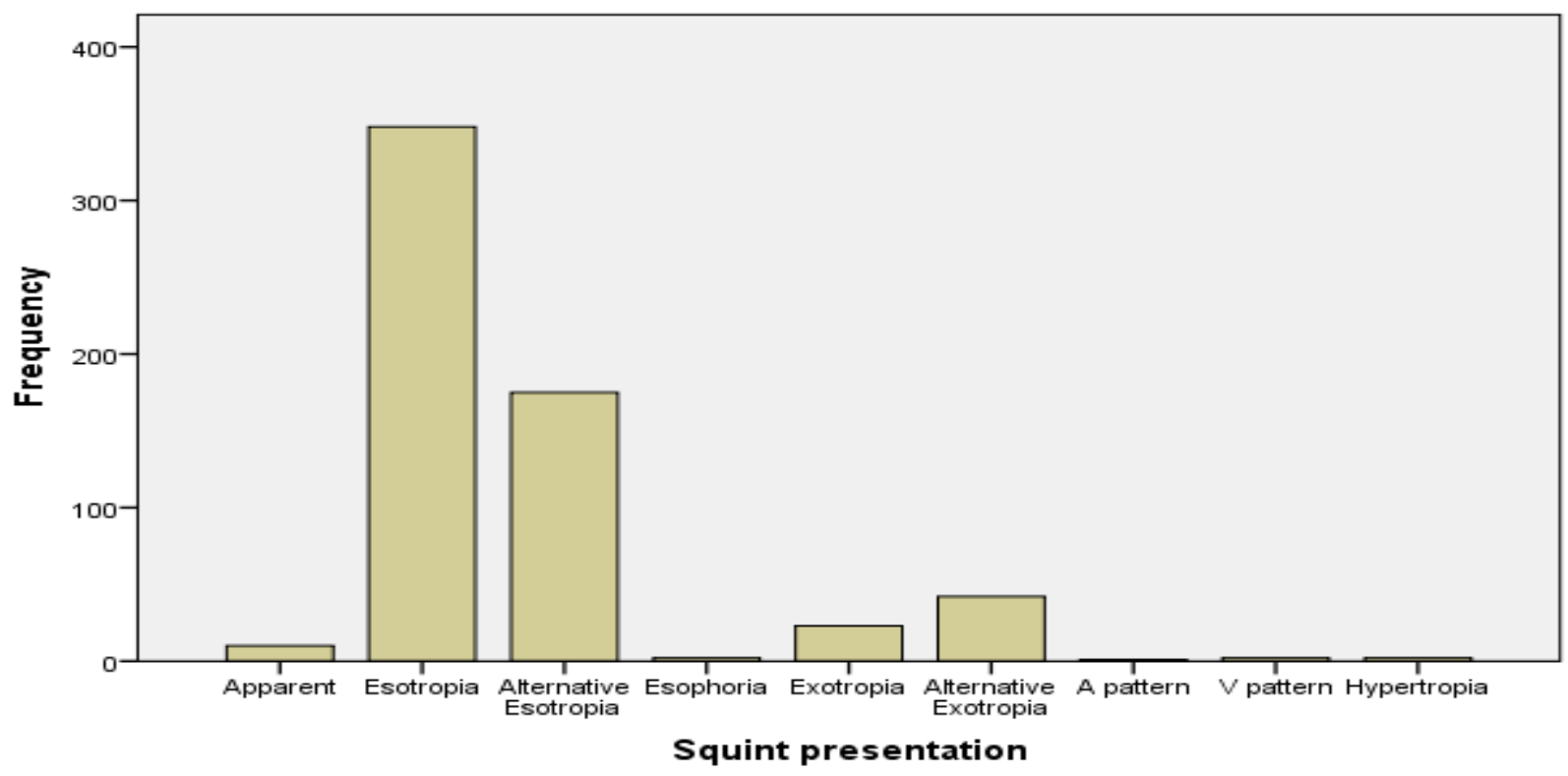

Figure 4:-frequency of different types of concomitant squint

\section{Refractive Errors Spherical Equivalent}

Hypermetropia was the most prevalent (79\%) refractive error among concomitant squint patients, while myopia was the least seen in only $6.9 \%$, and $14 \%$ were emmetropes, there was no sex preference in all types of refractive errors (Table1).

\begin{tabular}{|l|l|l|l|l|l|}
\hline \multirow{2}{*}{ Refractive errors } & Female & Male \\
\cline { 3 - 6 } \multicolumn{1}{|c|}{} & Frequency & Percent & Frequency & Percent \\
\hline \multirow{4}{*}{} & Emmetropia & 42 & 13.2 & 43 & 14.9 \\
\cline { 2 - 6 } & Hypermetopia & 249 & 78.5 & 229 & 79.5 \\
\cline { 2 - 6 } & Myopia & 26 & 8.2 & 16 & 5.6 \\
\cline { 2 - 6 } & Total & 317 & 100.0 & 288 & 100.0 \\
\hline
\end{tabular}

Table 1:-refractive errors presentation in different sex groups

\section{Family History And Consanguinity}

$63.6 \%$ (385) of the patients denied any family history of squint, and $81 \%$ (490) of them denied any history of consanguinity too, hypermetropia was the commonest refractive error in case of positive and negative family history and with almost identical presentation of $80 \%, 78.4 \%$ respectively.

In case of positive family history only $35.9 \%$ of the cases had history of consanguinity and $64.1 \%$ denied.

\section{Discussion:-}

Previous population-based studies of childhood strabismus had recognized a strong link between refractive errors and concomitant squint (2) (3), records about Libya was unremarkable beside the current conflicts in Libya and Benghazi specially many records were lost and irregular follow up, it was worthy to review the demographic records and study the risk factors and the situation to improve management and get the finest visual and binocular outcome and eradicate amblyopia.

Six hundred and five patients were registered in Marytr Souhil Alatrash eyes teaching hospitalsquint clinic 52.4\% were females with no much gender disparity (1.1:1) matching previous research from Vellore(3) of 1.2:1 female to male ratio ,76.5\% of them were presented before 6 years (mean age $5.076, \mathrm{SD}=3.4127$ ) which is near the critical time to eliminate the amblyopic jeopardy(6) on the other hand gender based disparity was obvious in presentation with mean age of $4.757( \pm 2.9834 \mathrm{SD}), 5.366( \pm 3.7417 \mathrm{SD})$ for males and females respectively ,this significant 
gender diversity was also noted previously claiming thatfemale patients are brought for management later not to inherent social implications and seeking a cosmetic solution mainly(3)(8) .

Although concomitant convergent squint is more prevalent with hypermetropia (9)(10)(11), hypermetropia could be used also as a predictor more than emmetropia(12) .In our study we found that hypermetropia and esotropia were most prevalent among concomitant squint patients this is going with results from pakistan (3)Saudi Arabia(13) ,Italy(14),Ethiopia and Nigeria (3)(17)(18), on the other hand myopia was the least prevalent with $6.9 \%(8.075: 1)$ of the cases ; this is totally contrasting the Chia A et al (15) study where myopia: hypermetropia represents 7:1and Yekta $\mathrm{A}(16)$ and also extotropia in contrast to our data where convergent squint predominates, this could be answered by the difference in ethanic races (13) between Caucasian and Asian race .

Family history of strabismus was denied in $63.6 \%$ of the cases and consanguinity too as in previous record (3), this can't be counted a reliable indicator as we mentioned earlier about the negative attitude regarding squint in community and denial is predicted too, although previous studies used both hypermetropia and family history as a srong predictor of hypermetropia .

\section{Conclusion:}

In patients registered in squint clinic at the Marytr Souhil Alatrash eyes teaching hospital in Benghazi earlier concomitant squint presentation was in male patients, esotropia and hypermetropia were the predominated elements, no significant relationship between family history and consanguinity and concomitant squint.

\section{Reference:-}

1. Hippocrates. On Airs, Waters, and Places. The Genuine Works of Hippocrates. New York: William Wood \& Co. $1886: 171$.

2. Maconachie GD, Gottlob I, McLean RJ. Risk factors and genetics in common comitant strabismus: a systematic review of the literature. JAMA Ophthalmol. 2013;131(9):1179-86.

3. Chopra V, Balasubramanian P, et al. Clinical study of concomitant squint. J. Evid. Based Med. Healthc. 2017; 4(54), 3294-3297. DOI: 10.18410/jebmh/2017/654

4. Sim B, Yap GH, Chia A. Functional and psychosocial impact of strabismus on Singaporean children. J AAPOS. 2014;18(2):178-82

5. Schuster, A., Elflein, H., Pokora, R., Schlaud, M., Baumgarten, F. and Urschitz, M. (2019). Health-related quality of life and mental health in children and adolescents with strabismus - results of the representative population-based survey KiGGS. Health and Quality of Life Outcomes, 17(1).

6. Scott WE, Stratton V13, Fabre J. Full-time occlusion therapy for amblyopia. Am. Orthopt. J. 1980; 30:125-130

7. Watson PG, Sanac AS, Picketing MS. A comparison of various methods of treatment of amblyopia: a block study. Trans. Ophthalmol. Soc. UK 1985; 104:319-328

8. Chaudhry TA, e. (2009). Gender differences and delay in presentation of childhood squint. -J Pak Med Assoc. 2009 Apr;59(4):229-31.

9. Anker S, Atkinson J, Braddick O, et al. Identification of infants with significant refractive error and strabismus in a population screening program using noncycloplegic videorefraction and orthoptic examination. Invest Ophthalmol Vis Sci. 2003; 44:497-504.

10. Ingram RM, Arnold PE, Dally S, Lucas J. Results of a randomised trial of treating abnormal hypermetropia from the age of 6 months. Br J Ophthalmol. 1990; 74:158-9.

11. Ingram RM, Walker C, Wilson JM, et al. Prediction of amblyopia and squint by means of refraction at age 1 year. Br J Ophthalmol. 1986; 70:12-5.

12. Cotter SA, Varma R, Tarczy-Hornoch K, McKean-Cowdin R, Lin J, Wen G, Wei J, Borchert M, Azen SP, Torres M, Tielsch JM, Friedman DS, Repka MX, Katz J, Ibironke J, Giordano L. Risk factors associated with childhood strabismus: The Multi-ethnic Pediatric Eye Disease and Baltimore Pediatric Eye Disease Studies. Ophthalmology 2011; 118: 2251-61.

13. Theodore H. Curtis, Maureen McClatchey, et al.Epidemiology of Surgical Strabismus in Saudi Arabia.Ophthalmic Epidemiology 2010; 17:5:307-314.

14. Coppola, G., Savastano, C., Ricci, V., Capobianco, A., Angrisani, A. and Ricci, B. Epidemiological of Strabismus Study in Italy Between 1999 and 2003Investigative Ophthalmology \& Visual Science May 2007, Vol.48, 4855. 
15. Chia A, Dirani M, Chan YH, et al. Prevalence of amblyopia and strabismus in young Singaporean Chinese children. Invest Ophthalmol Vis Sci 2010;51(7):3411-3417

16. Yekta A, Fotouhi A, Hashemi H, et al. Prevalence of refractive errors among schoolchildren in Shiraz, Iran. Clin Experiment Ophthalmol 2010a;38:242-248

17. Robaei D, Rose KA, Kifley A, Cosstick M, Ip JM, Mitchell P. Factors associated with childhood strabismus: findings from a population-based study. Ophthalmology 2006;113:1146-53

18. Azonobi IR, Olatunji FO, Addo J. Prevalence and pattern of strabismus in Ilorin. West Afr J Med 2009;28:2536. 